\title{
PRÁTICAS INFORMACIONAIS: ELEMENTOS CONSTITUINTES
}

\author{
INFORMATION PRACTICES: CONSTITUENTS \\ ELEMENTS
}

Janicy Aparecida Pereira Rochaa
Tatiane Krempser Gandra ${ }^{b}$

\begin{abstract}
RESUMO
Introdução: A partir de breve referência às abordagens tradicional e alternativa dos estudos de usuários, estas são contrapostas à abordagem social e aos estudos de práticas informacionais. Identifica-se e discute-se, posteriormente, os principais conceitos tradicionalmente abordados nesses estudos, a saber: usuário, contexto, informação, conhecimento e cultura. Objetivo: Apresentar a perspectiva das práticas informacionais, bem como a ressignificação dos referidos conceitos, o que se faz necessário para superar a perspectiva baseada em mecanismos de estímulo-resposta, adotada pelas duas primeiras abordagens, e para torná-los condizentes com essa nova forma de olhar para os fenômenos informacionais. Adicionalmente, apresenta outros conceitos propostos por diferentes autores: sociabilidade, imaginação simbólica, conhecimento autoritativo, autoridade cognitiva, credibilidade, resiliência informacional e posicionamento. Metodologia: Revisão da literatura da subárea usuários da informação buscando identificar: o modo como os conceitos são construídos em cada abordagem e os conceitos emergentes nas pesquisas sobre práticas informacionais. Resultados: Em uma compreensão mais ampla que as abordagens anteriores, as práticas informacionais se referem aos mais diversos modos de interação entre usuário e informação. Ao adotar a reconstrução dos conceitos-chave da subárea, assume-se que cada ação do sujeito é fruto de um duplo movimento entre sua subjetividade e os referenciais sociais. Portanto, é necessário compreender o significado que as ações dos usuários têm para eles mesmos e, também, desvelar a dimensão cultural por trás dessas ações. Conclusão: Para a abordagem de práticas informacionais, conceitos tradicionais da subárea devem ser reconfigurados de modo a se ajustar a visão mais compreensiva dessa perspectiva. Nesse sentido, a discussão de aportes teórico-metodológicos para estudos de práticas informacionais são relevantes para a subárea usuários da informação.
\end{abstract}

Descritores: Estudos de usuários. Práticas informacionais. Abordagem social. Contexto.

\footnotetext{
a Doutora em Ciência da Informação pela Universidade Federal de Minas Gerais (UFMG). Email: janicy.rocha@gmail.com

b Doutora em Ciência da Informação pela Universidade Federal de Minas Gerais (UFMG). Professora na Escola de Ciência da Informação da Universidade Federal de Minas Gerais (UFMG). E-mail: tatikrempser@gmail.com
} 


\section{INTRODUÇÃO}

A tradição da subárea estudos de usuários é tema recorrente em discussões e publicações da Biblioteconomia e da Ciência da Informação (Cl). Associadas a isso, referências à origem, ao histórico e ao quadro teórico dos estudos de usuário são frequentes na literatura. De forma geral, autores que abordam a temática apontam relativo consenso quanto à origem desses estudos estar relacionada ao surgimento da necessidade de se conhecer hábitos e perfis de usuários de bibliotecas na década de 1930 (GONZÁLEZ TERUEL, 2005; ARAÚJO, 2012; ARAÚJO, 2013).

A influência da origem do campo pode ser observada nos primeiros estudos realizados inicialmente com usuários e não-usuários de bibliotecas e, posteriormente, com grupos de cientistas, engenheiros e outros. Tais estudos objetivavam estabelecer indicadores demográficos das comunidades estudadas, com vistas a prover melhorias dos serviços de informação e também a avaliar tais serviços. A coleta de dados era realizada por meio de questionários; a tabulação de dados se valia de métodos estatísticos e os resultados visavam correlacionar dados objetivos como sexo, idade e profissão com ações dos usuários - tipo de fonte de informação acessada, frequência de acesso, tipos de necessidade que motivavam as buscas e outras.

Conforme Araújo (2013), por serem utilizados como "ferramentas de diagnóstico", ainda que voltados para as necessidades dos usuários, os estudos sob esse enfoque, pertencentes à chamada abordagem tradicional, distanciavam-se dos sujeitos, aproximando-se mais das bibliotecas e das fontes e sistemas de informação, em uma perspectiva conhecida como orientada ao sistema. Críticas à abordagem tradicional surgiram em função de sua orientação positivista e de limitações como a ausência de base teórica e a atenção direcionada apenas a aspectos externamente observáveis, desconsiderando aspectos subjetivos dos usuários.

Assim, em meados da década de 1980, surge a segunda forma de se estudar os usuários da informação, denominada abordagem alternativa ou cognitiva. González Teruel (2005) aponta que essa linha de investigação, orientada ao usuário, foca em características individuais - cognitivas e afetivas 
- que condicionam modos de busca e uso da informação pelo indivíduo, bem como o surgimento de suas demandas de informação. Desenvolvidos conforme a noção de comportamento informacional, esses estudos pressupõem que os indivíduos agem em reação à necessidade de informação (ARAÚJJ, 2013). Além disso, as necessidades são vistas como subjetivas e o usuário, como um sujeito individual capaz de produzir sentido à informação que acessa.

Apesar do avanço identificado nessa transição - como a incorporação de base teórico-metodológica; o privilégio às abordagens qualitativas; a ampliação do universo empírico; a mudança da percepção da informação de objetivas para subjetiva, etc. - a abordagem alternativa também recebeu críticas. Muitas delas pelo fato de considerar o usuário sendo movido por forças externas; outras por entender que o estado cognitivo do usuário se alterava ao receber novas informações; outras por priorizar aspectos subjetivos, não abarcando a influência da coletividade (GONZÁLEZ TERUEL, 2005; ARAÚJO, 2012; ARAúJO, 2013).

Então, na década de 1990 começou a se constituir a denominada abordagem social, ou sociocultural, cuja ênfase está no caráter intersubjetivo das ações dos usuários em contexto (ARAÚJO, 2013). Ao privilegiar a dimensão coletiva e entender que os fenômenos informacionais ocorrem em contextos específicos, pressupõe-se que muda a compreensão da interação do usuário com a informação. Consequentemente, é demandada uma nova forma de entendimento de muitos dos conceitos usualmente abordados nos estudos de usuários. Entre eles estão a informação, as necessidades de informação e os critérios de relevância, que deixam de ser vistos como algo externo ao usuário ou dependente apenas de sua subjetividade, para serem compreendidos enquanto construções sociais. Não se trata de apenas reconstruir cada conceito individualmente, mas eles só adquirem sentido entrelaçados entre si.

Estudos de usuário em conformidade com a abordagem social, apesar de partilharem essas características em comum, apresentam certa diversidade de perspectivas. Dados os limites desse artigo nos ateremos à perspectiva das práticas informacionais, alicerçada no socioconstrucionismo. Assim, o objetivo 
desse artigo ${ }^{1}$ é apresentar tal perspectiva, bem como a ressignificação de conceitos tradicionais na subárea, o que os torna condizentes com essa forma olhar para os fenômenos informacionais. Complementarmente, são apontados conceitos adicionais enfatizados por outros pesquisadores de práticas informacionais.

Para cumprir o objetivo proposto, a metodologia utilizada foi a revisão de literatura, cujas buscas ocorreram em fevereiro e março de 2017 no Portal de Periódicos da Coordenação de Aperfeiçoamento de Pessoal de Nível Superior (CAPES) e na Base de Dados Referenciais de Artigos de Periódicos em Ciência da Informação (BRAPCI). Foi utilizado o descritor "information practices" e seu correspondente em português "práticas informacionais". Nenhum recorte cronológico ou idiomático foi estabelecido. Recuperados os artigos, procedemos à análise de conteúdo dos mesmos por meio da qual foram identificados os elementos aqui apresentados e as formas como eles são conceituados em cada abordagem.

\section{PRÁTICAS INFORMACIONAIS: UM QUADRO CONCEITUAL}

Embora o termo práticas informacionais apareça na literatura da $\mathrm{Cl}$ desde a década de 1960, é apenas a partir dos anos 2000 que autores da subárea usuários da informação começam a debater o conceito de modo mais profundo. O termo ganha espaço ao ser mencionado como um contraponto ao conceito de comportamento informacional (SAVOLAINEN, 2007).

Para sustentar a perspectiva de práticas informacionais que defende, Araújo (2013) identifica na Etnometodologia a origem do conceito. Já Talja (2005) e Savolainen (2007) consideram o conceito como advindo da Sociologia e Antropologia. De forma geral, estudos sobre práticas informacionais são influenciadas por um paradigma socioconstrucionista (MCKENZIE, 2001; SAVOLAINEN 2007; OLIPHANT 2010; TALJA; NYCE, 2015).

Em uma das primeiras menções ao conceito, Marteleto (1994, p. 134)

Artigo desenvolvido conforme discussão teórica empreendida pelas autoras em suas respectivas teses (GANDRA, 2017; ROCHA, 2018). 
reforça sua origem antropológica, definindo prática informacional como "mecanismos de apropriação, rejeição, elaboração de significados e valores, não numa sociedade sincrônica, que guarda uma relação direta e cumulativa com a tradição, mas naquela onde os sujeitos elaboram suas representações", valorizando as experiências individuais e a pluralidade.

Já Talja, Tuominen e Savolainen (2005) delineiam o conceito de práticas informacionais ressaltando que os processos de busca e uso da informação são constituídos social e biologicamente, e não apenas a partir da cognição e motivações individuais, como defende a concepção de comportamento informacional. Talja (2005) salienta, ainda, que a característica essencial das práticas informacionais é a sua linha de investigação mais sociológica e contextualmente orientada.

No mesmo sentido, Araújo (2013) enfatiza a superação de algumas características mais restritas das abordagens tradicional e alternativa, propiciada pela noção de práticas informacionais. O autor destaca que, sob essa visão, o usuário deixa de ser percebido como um ser isolado de um mundo que o cerca. A mesma ponderação se aplica às noções de informação e conhecimento, assim como qualquer ação dos sujeitos, que não podem ser investigadas dentro de uma perspectiva individualista. Ele argumenta que a informação deve ser compreendida "[...] como produto de uma 'intersubjetividade', e, principalmente, com a percepção de que algo só se torna informação a partir de um contexto no qual atuam dimensões políticas, culturais, econômicas, jurídicas, tecnológicas, entre outras" (ARAÚJO, 2013).

Essa dualidade entre as dimensões individual e coletiva é um dos traços constituintes das práticas informacionais. A relação do sujeito com o mundo é sempre uma relação mediada por outras pessoas. Ele apreende a realidade e a representa de acordo com referenciais que são construídos coletivamente, mas que são redefinidos de acordo com a subjetividade de cada um. Esse movimento dialético deve ser levado em consideração ao se estudar como os usuários se relacionam com a informação.

Assim, percebe-se a interação como elemento chave para a concepção de práticas informacionais. A noção de interação, enquanto ação recíproca, 
evidencia o permanente processo dialético entre indivíduo e realidade, nos mais diversos sentidos. "O usuário não é totalmente determinado pelo contexto no [qual se] insere, nem é totalmente isolado ou alheio a ele; a determinação que o contexto exerce, é real, mas não é mecânica nem absoluta, é interpretada e alterada pelo sujeito" (ARAÚJO, 2012, p. 149).

Tal correlação entre sujeito e realidade é construída e mediada pela dimensão da linguagem, como defendem Tuominen e Savolainen (1996) e Talja (1996). É por intermédio dela que os referenciais, valores, regras e normas da sociedade, dentre outros, são transmitidos e incorporados pelos sujeitos. É por meio dela, também, que o conhecimento e a cultura são criados e partilhados (WHITE; DILLINGHAM, 2009). Os sujeitos podem se posicionar de diferentes modos diante dessa realidade que a eles se apresenta, o que acarreta na criação de discursos e visões de mundo que se confrontam ou convergem. Há, então, uma negociação de significados e de discursos o tempo todo. E cada ação do sujeito representa uma interferência nesse campo de negociação ininterrupto.

Outra alteração relevante é a percepção de que a relação dos sujeitos com a informação não ocorre sempre devido a uma necessidade de informação ou um estado anômalo de conhecimento. Nem sempre há um problema a se resolver que demanda do usuário uma busca efetiva de informação para solucioná-lo. Entende-se que a interação com a informação acontece das mais variadas formas e o sujeito pode se deparar casualmente com ela ou buscá-la por simples prazer ou curiosidade (MCKENZIE, 2003; TALJA; NYCE, 2015).

Embasados por tais conjecturas, autores da subárea têm se apropriado de modo distinto da noção de práticas informacionais, dando ênfase a diferentes elementos ou dimensões que as constituem e que podem se apresentar de modo mais ou menos intenso em cada ambiente e/ou situação investigada. Embora não seja sempre mencionado, percebe-se que estudos sobre a temática adotam um olhar etnográfico, a partir do momento em que se valem de observações de campo e buscam compreender o significado que o comportamento dos usuários tem para eles mesmos.

Compreendemos que, sob a lente desses pressupostos explicitados, 
conceitos tradicionalmente abordados nos estudos de usuários são ressignificados. O intuito é a superação da lógica que fundamenta os modelos de investigação das abordagens tradicional e alternativa, que consideramos serem baseados em mecanismos de estímulo-resposta e que assumem o usuário enquanto ser isolado de tudo ao seu redor. Ao reconstruir tais conceitos, buscamos torná-los condizentes com essa nova forma de se olhar para os fenômenos informacionais. Nas seções 2.1, 2.2, 2.3, 2.4 e 2.5 são apresentados os cinco principais conceitos que assumem novos significados nos estudos de práticas informacionais.

\subsection{Usuário}

Usualmente, na $\mathrm{Cl}$, o indivíduo que estabelece alguma forma de contato com a informação é denominado usuário da informação. Entretanto, a literatura aponta que não há unanimidade em relação ao termo mais adequado para se referir àquele que se destaca como objeto de estudo da subárea estudo de usuários. Apesar da predominância do termo usuário, já consolidado no Brasil, vocábulos alternativos como cliente, interagente e outros são comuns na literatura (VERGUEIRO, 2002; DIAS; PIRES, 2004; CORRÊA, 2014). A escolha de um termo em detrimento de outro geralmente ocorre a partir de características do fenômeno investigado, do foco da pesquisa ou, ainda, de ressalvas feitas a esses diversos termos.

Para Dias e Pires (2004) o termo usuário é associado àqueles que utilizam bases de dados, bibliotecas e centros de informação; já cliente é associado a estudos relacionados à Administração ou ao Marketing. Vergueiro (2002) entende que usuário sugere passividade a quem utiliza serviços de informação, defendendo o uso de cliente, a quem os produtos e serviços devem estar focados. Por outro lado, Lunardelli (2004, p. 97) entende que o termo usuário evoca "[...] o ato de usufruir, de utilizar, ao passo que o vocábulo cliente está relacionado com a ideia de depender de alguém para obter ou ter acesso a algo", sendo, portanto, cliente menos ativo que usuário.

Ao discutir a pertinência do vocábulo usuário para definir o "sujeito que busca informação", Corrêa (2014, p. 37) defende o uso do termo interagente 
para "referir-se ao sujeito social e cognitivo que busca informação com vistas a solucionar questões de ordem pessoal, profissional ou acadêmica e que conta com o bibliotecário na condução desse processo de forma mais interativa e parceira". Essa proposição é fundamentada nas noções de interação e interatividade encontradas pela autora na literatura de estudos de usuários a partir da década de 1970, bem como na abordagem interacionista de estudos de usuários de informação apresentada por Araújo (2012).

A proposta da abordagem interacionista surge de um diálogo estabelecido entre a tradição e as tendências atuais dos estudos de usuários da informação. A perspectiva sugere que (i) o usuário não é totalmente determinado pelo contexto, nem totalmente alheio a ele, portanto, o usuário interpreta e altera a influência contextual; (ii) o significado da informação que existe no documento é interpretado pelo usuário; (iii) o usuário é um ser social que constrói o coletivo e é por ele construído e (iv) o acesso e o uso da informação não são apenas uma ação cognitiva, mas também uma ação emocional, cultural, contextual (ARAÚJO, 2012).

Essa forma de compreensão do indivíduo, ainda chamado de usuário pela abordagem interacionista, bem como da relação que ele estabelece com a informação e o social/coletivo excede os limites da concepção de usuário como utilizador de recursos e fontes informacionais. A perspectiva sugerida indica 0 surgimento de um indivíduo que não apenas usa, mas também produz e dissemina a informação em um contexto sociocultural. Esse é um tipo particular de sujeito, agora denominado sujeito informacional (ARAÚJO, 2013), termo mais condizente com abordagens de pesquisa que priorizam sujeitos sociais ativos que interagem com a informação e a constroem intersubjetivamente. Estudos de usuário com esse enfoque têm sido identificados como pertencentes à abordagem sociocultural.

Entendemos que investigações sobre práticas informacionais - conforme a concepção que defendemos - se enquadram na abordagem sociocultural dos estudos de usuários. Por adotar uma postura de compreensão do sujeito como indissociável do contexto sociocultural e da informação como construção social, acreditamos que a adoção do conceito de sujeito informacional em pesquisas 
sobre práticas informacionais é apropriada. Sujeito informacional não representa apenas um novo termo, mas também uma importante ressignificação para o conceito de usuário. Todavia, ao sugerirmos a reelaboração desse conceito, não visamos invalidá-lo, pois ele continua apropriado para pesquisas com outras perspectivas.

\subsection{Contexto}

A falta de consenso quanto ao conceito de contexto na área de estudo de usuários levou Dervin (1997, p. 14) a afirmar que "[...] não há um termo mais usado, menos definido e, quando definido, o é de formas tão diversas como contexto". Revisões de literatura feitas por Savolainen (2006) e Courtright (2007) demonstram que diferentes autores utilizam termos diversos para se referir a tal vocábulo. Savolainen (2006) identificou que fatores espaciais influenciam a definição de contexto em estudos de busca de informação, sobretudo nas etapas de seleção e uso. Devido a isso, é comum o uso de metáforas espaciais tais como ecologia informacional (information ecology); terreno informacional (information ground); horizonte informacional (information horizon); pequeno mundo (small world) e outros (SAVOLAINEN, 2006). Por sua vez, Courtright (2007) identificou termos como cenário (setting); ambiente (environment) e mundo informacional (information world), entre outros. Não obstante tais variações, Courtright (2007) e Tabak (2014) buscam apoio em Vakkari, Savolainen e Dervin (1997) ao afirmar que o contexto é geralmente entendido como um "quadro de referência" para o comportamento informacional ${ }^{2}$.

Talja e Nyce (2015) afirmam que existem duas principais linhas de raciocínio por meio das quais o contexto pode ser entendido: (i) contexto como sinônimo de situação e (ii) contexto como uma unidade mais ampla que

\footnotetext{
2 Courtright (2007) usa os termos comportamento informacional e práticas informacionais sem fazer distinção entre ambos, além do termo Information Needs, Seeking and Use (INSU) para se referir ao campo que no Brasil se convencionou chamar de estudo de usuários. Já Tabak (2014) faz distinção entre comportamento informacional e práticas informacionais, mas também usa o termo Information Behavior (IB) como campo de pesquisa equivalente a estudo de usuários.
}

Inf. Inf., Londrina, v. 23, n. 2, p. 566 - 595, maio/ago. 2018. http://www.uel.br/revistas/informacao/ 
situação. Adotando a primeira forma, contexto refere-se às circunstâncias nas quais as necessidades de informação surgem. Já a segunda forma, condizente com as lentes da prática, considera que em determinado contexto podem surgir vários tipos de situação. Situações fazem parte das atividades rotineiras, sejam elas relacionadas ao trabalho ou à vida cotidiana e o contexto assume maior amplitude, sem fronteiras bem delimitadas, por ser construído por meio de interações sociais e/ou coletivas.

Além dessas divergências relacionadas às formas de referência e de entendimento do contexto, observa-se na literatura certa diversidade quanto às formas de se abordar o contexto. Após extensa revisão de literatura, Courtright (2007) identifica cinco diferentes abordagens, a saber: (i) contexto como invólucro (context as container); (ii) contexto como significado construído (context as construted meaning); (iii) contexto como socialmente construído (socially constructed context); (iv) contexto relacional (relacional context) e (v) contexto dinâmico (changing context).

A primeira abordagem, positivista, entende o contexto como um invólucro dentro do qual estão o indivíduo e diversas variáveis passíveis de enumeração, como condições socioeconômicas, papéis, tarefas e outros. $O$ contexto, entendido dessa forma, considera a realidade como objetiva; um cenário no qual se assume que as variáveis citadas direcionam as ações dos usuários. Courtright (2007), então critica o fato de que, geralmente, o contexto é abordado apenas na introdução das pesquisas, não sendo problematizado em relação aos dados na explicação do comportamento do usuário. Outra crítica é direcionada ao fato de o contexto ser apenas um "pano de fundo" em pesquisas que não abordam efetivamente os significados a ele atribuídos pelos sujeitos, nem elementos que ultrapassem os limites do invólucro.

A segunda abordagem, construtivista, aborda o contexto como significado construído a partir do ponto de vista do usuário, cujo comportamento é influenciado por variáveis contextuais relacionadas às dimensões fisiológicas, emocionais, psicológicas, bem como aos papéis e ambientes de atuação dos atores (COURTRIGHT, 2007). Conforme a autora, tais variáveis, bem como a avaliação de risco/recompensa e as experiências 
anteriores do indivíduo são capazes de inibir ou impulsionar suas ações relacionadas à informação. Essa abordagem é criticada por considerar que a informação e o contexto são construções puramente individuais.

A terceira abordagem, socioconstrucionista, surge como respostas às críticas direcionadas ao contexto como significado construído, mediante o argumento de que os sujeitos são seres sociais (COURTRIGHT, 2007). O contexto é, então, considerado como uma construção social e, portanto, não pré-existe ao indivíduo. Os sujeitos, como seres sociais, interagem em comunidades específicas permeadas por normas, valores e referenciais que são internalizados em graus distintos. Logo, informação e conhecimento são construções sociais resultantes dessas interações. Adotar essa abordagem implica em estudar a linguagem, mais que observar comportamentos e registrar opiniões, pois é por meio dela que se revela a construção social da realidade.

A quarta abordagem - o contexto relacional - considera fatores institucionais e tecnológicos integrados nas atividades informacionais, concebendo contexto e ator como indissociáveis. Ao contrário da abordagem de contexto como invólucro, aqui o contexto não é um cenário que pode ser descrito; ele é produzido pelas interações entre atores humanos e não humanos. Além disso, durante a pesquisa, o pesquisador e o olhar que este direciona aos dados também influenciam na criação do contexto (TALJA; KESO; PIETILÄINEN, 1999; DOURISH, 2004; COURTRIGHT, 2007).

$\mathrm{Na}$ quinta abordagem - o contexto dinâmico - atores e contexto se moldam mutuamente, de forma constante. Portanto, se o contexto relacional já implica em certo grau de mudança, esta se torna a característica essencial e marcante do contexto dinâmico. Embora estruturas e recursos sejam considerados, a atividade humana é privilegiada nessa abordagem (COURTRIGHT, 2007).

Diante dessa divergência conceitual, tanto na nomenclatura, quanto nas formas de entendimento e de abordagem do contexto, apresentamos, então, uma noção que consideramos condizente com a concepção de práticas informacionais que defendemos. $O$ fato de o fazermos não significa que termos equivalentes ou outras formas de entendimento não possam ser adotados em 
estudos em conformidade com outras perspectivas. Inclusive, devido à relevância do contexto em estudos de usuários, julgamos fundamental que sua compreensão seja coerente com a postura de pesquisa adotada.

Quanto à nomenclatura, consideramos que termos que fazem referências a elementos espaciais - como cenário, terreno informacional, pequeno mundo, entre outros - transmitem a ideia de demarcação. Considerar o contexto como delimitado remete ao entendimento deste como invólucro, o que seria mais condizente com os estudos de usuário conforme a abordagem tradicional. Já a forma de entendimento de contexto como equivalente a situação se aproxima dos pressupostos assumidos pela abordagem alternativa, bem como ao contexto como significado construído, identificado por Courtright (2007). Estudos de comportamento informacional, típicos dessa abordagem, assumem que situações problemáticas desencadeiam necessidades de informação e que, nessas situações, existem variáveis que interferem no processo de busca e uso da informação.

Portanto, em estudos de prática informacionais, defendemos o uso do termo contexto, em detrimento tanto de seus equivalentes relacionados a metáforas espaciais, quanto ao de seu entendimento como situação. A palavra contexto, tradicionalmente utilizada no campo, é definida como um "conjunto de circunstâncias inter-relacionadas de cuja tessitura se depreende determinado fato ou situação" (MICHAELIS, 2017), o que transmite a noção de maior amplitude e complexidade desse conceito. Isso vai ao encontro da segunda linha de pensamento de Talja e Nyce (2015), corroborando com nossa visão de como se deve abordar o contexto em estudos de práticas informacionais.

Pelo fato de estudos sobre práticas informacionais geralmente adotarem uma perspectiva sociocontrucionista, a abordagem do contexto como socialmente construído, a princípio, seria a mais indicada para pesquisas com esse enfoque. Todavia, para a nossa concepção de práticas informacionais, consideramos que as duas últimas abordagens identificadas por Courtright (2007) - contexto relacional e contexto dinâmico - possuem características que complementam o entendimento de contexto como socialmente construído. 
O contexto como socialmente construído não menciona os atores nãohumanos como integrantes do contexto, nem a participação dos pesquisadores em sua construção. Estes estão presentes na abordagem relacional que, ao considerar que a interação entre os atores humanos e não-humanos forma 0 contexto, também introduz a noção de mudança. Porém, é na abordagem dinâmica que tal mutabilidade recebe maior ênfase, assim como o privilégio dado à atividade humana.

Diante do exposto, delineamos um entendimento de contexto, compatível com nossa concepção de práticas informacionais. Ao considerarmos apropriadas e complementares as diferentes características das últimas três abordagens de contexto citadas por Courtright (2007), há um grande salto em complexidade no conceito de contexto. Especialmente no que tange à já dita atividade humana e à interação entre atores e contexto, o que implica conceber a influência dos precedentes históricos dos usuários, seus interesses e os aspectos econômicos, culturais e políticos, dentre outros. Tais aspectos são inerentes à interação dos sujeitos com tudo o que os cerca, inclusive com a informação.

Ao privilegiar a atividade humana, reconhecemos que a cultura é uma construção dos seres humanos e as práticas informacionais são, em essência, práticas coletivas, culturais. Portanto, acreditamos que, embora os atores nãohumanos (tecnologias, estrutura e recursos, entre outros) sejam importantes e influenciam a construção do contexto, a centralidade está na interação entre os sujeitos (atores humanos). Mesmo que atores não-humanos atuem sobre a cultura, há sempre a intencionalidade humana por trás dessa ação. Então, o que torna tão complexo esse conceito é uma constante construção mútua (a dinamicidade) entre atores e contexto, ambos continuamente sendo modificados ou influenciados por todas as características, elementos ou aspectos inter-relacionados na realidade dos sujeitos.

\subsection{Informação}

A informação é um conceito primordial nos estudos da $\mathrm{Cl}$, enquanto objeto desse campo de estudos, e apresenta, também, fundamental 
importância para os estudos da subárea usuários da informação. Apesar de tal relevância, ainda não há um consenso a respeito desse conceito, existindo inúmeras definições e concepções de informação presentes na literatura (BARRETO, 1994; SARECEVIC, 1996; ROBREDO, 2003).

Muitos teóricos se empenham na tentativa de chegar a uma definição sobre o conceito. Destas inúmeras tentativas, sobressaem-se algumas noções de informação na $\mathrm{Cl}$ que, em diferentes níveis, manifestam-se de modo semelhante nas várias subáreas do campo, dentre as quais a de usuários da informação. A seguir, expomos as ideias de alguns autores que assinalam três principais noções da informação na $\mathrm{Cl}$ - físico, cognitivo e intersubjetivo. Buscamos, então, desvelar cada uma destas concepções e aproximá-las do entendimento de informação, ressignificado nas diferentes abordagens dos estudos de usuários.

Araújo (2013) aponta que autores como Rendón Rojás (1996), Saracevic (1999), Ørom (2000), Hjørland (2000), Fernández-Molina e Moya-Anegón (2002) e Capurro (2003) apresentam ideias convergentes sobre as três diferentes concepções de informação predominantes identificadas na $\mathrm{Cl}$. A primeira delas é a de informação enquanto uma entidade física e objetiva, cujo cerne está nos aspectos tangíveis e na recuperação da informação. Focada na mensagem/informação, que é tratada de forma isolada, essa noção não contempla os aspectos semânticos e pragmáticos dos fenômenos informacionais. Tal entendimento se aproxima da concepção adotada na abordagem tradicional, na qual a informação teria um significado fixo, independente da interpretação dos sujeitos.

A segunda concepção de informação passa a considerar aspectos qualitativos da interação dos sujeitos com os sistemas de informação, privilegiando a dimensão cognitiva dos usuários, que dão significado à informação. Essa noção mostra-se mais ampla que a primeira e aproxima-se da ressignificação pela qual o conceito de informação passa na abordagem alternativa dos estudos de usuários. Tentando responder às críticas sofridas pela abordagem tradicional, aqui a informação é compreendida como uma construção subjetiva que preenche lacunas na mente dos usuários, sendo 
capaz de solucionar problemas e reduzir incertezas (RENDÓN ROJÁS, 1996; SARACEVIC, 1999; ØROM, 2000; HJØRLAND, 2000; FERNÁNDEZ-MOLINA, MOYA-ANEGÓN, 2002; CAPURRO, 2003).

Por fim, a terceira noção tem a informação como uma construção intersubjetiva. Rendón Rojás (1996), Saracevic (1999), Ørom (2000), Hjørland (2000), Fernández-Molina e Moya-Anegón (2002) e Capurro (2003) destacam a essência integradora dessa concepção de informação, evidenciando que todos os processos informacionais são constituídos coletivamente, dentro de contextos socioculturais nos quais os sujeitos e grupos constroem e partilham critérios de seleção e relevância. Ademais, os autores entendem que, além da dimensão cognitiva, a motivação e a intencionalidade também permeiam a construção da informação. Essa ressignificação, que fornece um ganho na complexidade do conceito de informação, corresponde à noção adotada na abordagem social dos estudos de usuários e das práticas informacionais.

A informação passa a ser compreendida como um processo que abarca diferentes dimensões: sua manifestação física ou material e a interpretação cognitiva dos sujeitos, cujo significado depende, também, da interação do usuário - sujeito dotado de historicidade e intencionalidade - com a informação e com o contexto político e sociocultural no qual ele se apropria da informação. Tal movimento de ressignificação não implica em negar as concepções anteriores, mas trata-se de uma dinâmica de ampliação do conceito.

\subsection{Conhecimento}

Intrinsecamente ligada ao conceito de informação, está a concepção de conhecimento. Assim como os demais elementos tradicionalmente presentes nos estudos de usuários, esse conceito é percebido de maneira diferente nas abordagens da subárea. Não se trata de uma simples mudança na descrição do conceito, mas de uma forma de se enxergar a realidade, o que implica em uma nova correlação entre os demais conceitos discutidos neste artigo.

$\mathrm{Na}$ abordagem tradicional, o conhecimento é percebido como algo estritamente objetivo e externo ao sujeito. Assume-se a noção de que existe uma verdade única ou absoluta a respeito de todas as coisas com as quais as 
pessoas se relacionam. Entendido dessa forma, a noção de conhecimento pretere uma série de circunstâncias referentes tanto aos usuários (como a historicidade e bagagem prévia de cada um), quanto aos objetos da realidade (como as mais variadas formas de expressão da informação, que sofrem influência de outros sujeitos e instituições mediadoras que possuem suas próprias visões de mundo, por exemplo).

Já na abordagem alternativa, o conceito de conhecimento deixa de ser presumido como algo externo aos usuários e é entendido como um processo de acumulação. Esse é o pressuposto fundamental: que o conhecimento que pertence a uma pessoa se transforma em outro estado de conhecimento toda vez que uma nova informação é assimilada. Embora essa noção inclua o sujeito na equação, representando um avanço em relação à abordagem tradicional, a abordagem alternativa ainda sofre críticas por deixar de lado os condicionamentos sociais, culturais e materiais da sociedade na construção do conhecimento.

Por fim, na abordagem social e nos estudos de práticas informacionais há significativa alteração no entendimento de como as pessoas conhecem o mundo ao seu redor. Assume-se que o conhecimento é uma construção social resultante da interação entre pessoas e delas com a realidade.

No estudo das práticas informacionais, assume-se que o sujeito se relaciona com a realidade de variadas maneiras, não apenas pela mente, mas também pelos seus sentimentos e interesses, dentre outros. O conhecimento é, então, entendido como um processo dialético de assimilação e acomodação. É um processo permanente de construção mútua de significados (GANDRA; ARAÚJO, 2016).

O pressuposto que sustenta essa concepção é a noção de assimilação e acumulação, de Piaget (1996). Segundo o autor, cada pessoa possui uma estrutura prévia de conhecimentos e quando recebe um novo estímulo, ocorrem os processos de assimilação e acomodação, alterando essa estrutura. Esse processo não é homogêneo, ocorrendo de diferentes maneiras para cada pessoa, devido à historicidade e características individuais de cada um.

Percebe-se uma convergência entre as ideias Piaget (1996) e Freire (2007), como já apontado por Gandra e Araújo (2016). Freire (2007) argumenta 
que o conhecimento não se refere a processos de repetição e memorização. Ele afirma que, nesses casos, não há apreensão do real significado do conteúdo que é 'depositado' fora de contexto. Ele defende, também, que "só existe saber na invenção, na reinvenção, na busca inquieta, impaciente, permanente, que os homens fazem no mundo, com o mundo e com os outros" (FREIRE, 2007, p. 67). Portanto, o conhecimento não é fruto da atividade individual de um sujeito, mas é compreendido como uma construção da coletividade, que só pode existir na interação entre as pessoas e delas com a realidade.

\subsection{Cultura}

Embora a maioria dos estudos das abordagens tradicional e alternativa não apresente uma discussão explícita a respeito do conceito de cultura, entendemos que é uma noção essencial para construção da perspectiva das práticas informacionais, pois a cultura pode ser compreendida como a dimensão que interconecta todas as demais, uma base para todos os elementos reconstruídos. Pensando na abordagem tradicional de um modo mais geral, podemos considerar que esses estudos deixam de lado a dimensão cultural ao investigar usuários, informação e sistemas de informação. A influência da cultura nessa relação é, portanto, desconsiderada.

Já na abordagem alternativa, percebe-se que o conceito de cultura é assumido em uma lógica de acumulação, da mesma forma como a noção de conhecimento nessa abordagem. Um sujeito, então, teria um estoque de conhecimento e cultura acumulados. A dimensão sociocultural que nos cerca é considerada como algo externo ao indivíduo e teria a capacidade de influenciar - positiva ou negativamente - o processo de busca e uso da informação por parte do usuário.

$\mathrm{Na}$ abordagem das práticas informacionais há uma expressiva reconstrução da noção de cultura. Ao se investigar a interação entre usuários e informação, busca-se a relação de cada ação do sujeito com a cultura e com os referenciais sociais que o cerca. Esses referenciais, é importante salientar, são constituídos por nós mesmos e nos constituem, mutuamente. 
White e Dillingham (2009) afirmam que o homem e cultura são inseparáveis e que a cultura é realizada pela simbologização. Simbologizar, segundo elas, é a capacidade que os homens têm de originar, definir e atribuir significados - de forma livre e arbitrária - às coisas e acontecimentos no mundo externo, bem como de compreender esses significados. Na mesma direção, Geertz (2014, p. 4), alega que o homem é "um animal amarrado a teias de significados que ele mesmo teceu, assumindo a cultura como sendo essas teias e a sua análise."

Os significados dos objetos que cercam as pessoas (as palavras, a escrita, as ações, etc.) não são inerentes a esses objetos. De acordo com White e Dillingham (2009), eles não podem ser compreendidos apenas com os cinco sentidos do corpo humano. Essa compreensão só se torna possível por causa da capacidade de simbologização do homem.

A todo o momento o sujeito recorre a essa teia de significados ao interagir com objetos da realidade, inclusive nas interações que estabelece com a informação. $O$ sujeito recorre aos seus valores e aos referenciais sociais para interpretar a realidade que o cerca e, assim, pode dar significado a ela. A dimensão sociocultural nos estudos das práticas informacionais revela-se como mais do que uma variável que interfere no comportamento dos sujeitos. Tal dimensão é constituinte de suas ações, pensamentos e opiniões.

\section{ELEMENTOS ADICIONAIS DEFINIDOS POR DIFERENTES AUTORES}

Além desses cinco elementos, usualmente adotados em estudos de práticas informacionais, alguns autores propõem outros elementos, cujo potencial para tais estudos é por eles defendido. A apropriação desses elementos adicionais se mostra pertinente dada a complexidade das diversas possibilidades de interação entre usuário e informação. Assim sendo, apresentamos a seguir alguns desses elementos. Não se trata, porém, de uma revisão sistemática de literatura, dados os limites desse artigo.

Araújo (2015) destaca dois conceitos que podem contribuir para a consolidação de uma base conceitual para os estudos das práticas informacionais. O primeiro é o de imaginação simbólica, que, segundo o autor, 
é essencial para superar o cunho mais restrito das abordagens tradicional e alternativa, visto que não existe apreensão da realidade sem a noção de imaginação simbólica. Ela pode ser entendida como a capacidade do homem de criar, representar e simbolizar tudo o que o cerca, já que, conforme Rendón Rojás (2005), o mundo natural não possui significado por si mesmo. São as formas simbólicas que permitem aos sujeitos experimentar e compreender a realidade, para dar significado ao que eles percebem.

Então, para decodificar os símbolos é indispensável que o sujeito cognoscente empregue mais que apenas suas capacidades intelectuais puras. São necessárias, também, a fantasia, a imaginação e a criatividade (RENDÓN ROJÁS, 2005). Em consonância, Araújo (2015) salienta que nós apreendemos o mundo de duas maneiras. A primeira é o modo direto, por meio dos nossos cinco sentidos. E a segunda forma é o modo indireto, quando da ausência do objeto, pela dimensão simbólica, representando e atribuindo significado às coisas do mundo. Até mesmo pelo modo direto, através dos sentidos, o sujeito apreende o mundo atribuindo significado às coisas, característica intrínseca ao ser humano, que não consegue conhecer a realidade sem representar, classificar e atribuir significados aos objetos do mundo (DURAND, 1993).

Esse processo incessante de criação de significado que o homem faz em relação a tudo com o que interage é a marca do campo da imaginação simbólica, das formas de apreensão indireta da realidade, quando fazemos representações que remetem aos objetos. Isso é o que nos permite "abrir as portas para o novo e, ao fazer isso, estende a realidade" (ARAÚJJO, 2015, online). Trata-se de uma das funções da imaginação simbólica, a teofânica: esse processo interminável de criação de sentido que sempre resulta em algo novo. Por isso mesmo, a nossa relação com a realidade nunca é completa e absoluta, mas está sempre em construção.

Araújo (2015) aponta, também, o potencial do conceito de sociabilidade para superar o viés isolacionista dado ao usuário nas abordagens tradicional e alternativa. O homem não existe sozinho ou isolado no mundo, mas ele é um ser com os outros, compartilhando uma realidade com outros sujeitos e objetos. Sua ação se dá, portanto, inclusive em função dos outros; seja com 
um objetivo ou interesse que norteia a ação ou pelo puro desejo de estar com outros em uma relação.

A sociabilidade pode ser definida, então, como uma forma de associação entre os sujeitos, que é marcada pela inexistência de fins práticos. Trata-se da relação que acontece por si mesma, os momentos nos quais "os indivíduos se comprazem em estabelecer laços, e esses laços têm em si mesmos sua razão de ser" (FRANÇA, 1995, p. 60). No que concerne ao estudo dos fenômenos informacionais, isso implica considerar que as práticas informacionais ocorrem, também, em meio a outras práticas cotidianas dos sujeitos, no campo da sociabilidade.

Consideramos pertinente a apropriação do conceito de imaginação simbólica, primeiramente, porque o símbolo é a base da cultura (WHITE; DILLINGHAM, 2009) e esta é característica constituinte da interação do sujeito com a informação. E, também, a imaginação é uma dimensão inerente do ato de criação, de construção do conhecimento, outro elemento basilar das práticas informacionais. No que tange à sociabilidade, acreditamos que 0 sujeito não busca a informação apenas quando tem um problema ou quer reduzir incertezas, como postula a abordagem alternativa. Mas ele pode se deparar com a informação casualmente ou mesmo buscá-la por interesses diversos ou prazer, como salienta Talja e Nyce (2015). Além disso, outros elementos primordiais das práticas informacionais, como o conhecimento e a cultura, só podem ser construídos a partir da relação entre os homens e com o mundo, o que perpassa pela sociabilidade.

A construção de autoridade acerca das fontes informacionais, humanas e não-humanas, é um elemento enfatizado por McKenzie (2003) e Oliphant (2010). Ambas as autoras defendem que tal elemento, originário de referenciais subjetivos e intersubjetivos, interfere nas práticas informacionais, pois a autoridade da fonte de informação é determinante em sua escolha. A autoridade é entendida como construída a partir da inter-relação de três principais conceitos: conhecimento autoritativo ${ }^{3}$ (authoritative knowledge);

\footnotetext{
3 A palavra 'autoritativo', inexistente em português, é usada na literatura como um neologismo. Gadamer (1993) define autoritativo como o reconhecimento da autoridade de alguém sem que haja arbitrariedade ou imposição e relaciona o vocábulo à palavra autoridade, entendida como o exercício de poder para
} 
autoridade cognitiva (cognitive authority) e credibilidade (credibility).

Segundo Oliphant (2010, p. 49, tradução nossa), o conhecimento autoritativo é aquele "que tem o poder de influenciar e, talvez, também impor obediência”. A autora baseia tal afirmação na concepção de Jordan (1997), para quem o conhecimento autoritativo é aquele considerado legítimo dentro de uma comunidade, se destacando a ponto de influenciar decisões e cursos de ações. Embora se destaque, ele não é imposto; sua legitimidade é construída por meio da negociação discursiva que leva ao consenso.

A autoridade cognitiva, conceito cunhado por Wilson (1983), fundamenta-se na ideia do reconhecimento de alguém que conhece aquilo sobre o qual fala (who knows what about what) e influencia quem o reconhece como tal. Autoridades podem ser pessoas, organizações, instituições, textos e outros, mas não por imposição a partir de posição hierárquica, situação ou qualquer outra forma. São particularidades da autoridade cognitiva: (i) envolver pelo menos dois atores, pois algo não pode se eleger autoridade para si mesmo; (ii) não ser obrigatoriamente bidirecional - "A" ser autoridade para "B" não implica em "B" ser autoridade para "A"; (iii) ser questão de grau - pode ter muitas ou poucas em dada área - e de peso e valor - postulações de " $A$ " devem ser relevantes para "B"; (iv) variar conforme a esfera de interesse - "A" pode ser autoridade em um assunto, mas não ser em outro.

Por fim, a autoridade cognitiva está diretamente relacionada à credibilidade. Conforme Wilson (1993), uma autoridade cognitiva só consegue exercer e manter a influência se ela for considerada crível e, para tal, ela precisa ser competente e confiável. Entretanto, nem sempre um ator crível exerce suficiente influência sobre os demais a ponto de se tornar uma autoridade em sua área.

Entendemos que a apropriação da noção de autoridade, baseada nesses três conceitos apresentados, é relevante para os estudos de práticas informacionais por, muitas vezes, ser determinante para as ações dos sujeitos informacionais, se considerada como critérios de relevância, avaliação, seleção e uso da informação. Entretanto, é preciso se atentar ao fato de que a 
legitimação de um tipo de conhecimento em detrimento de outros - ainda que importante para a seleção e uso de fontes informacionais - traz consequências como a desvalorização ou a rejeição de outros saberes e o tensionamento das relações de poder dentro de uma comunidade.

Lloyd $(2014,2016)$ desenvolve estudos nos quais relaciona competência informacional e práticas informacionais sobre a saúde de refugiados. Nesses estudos é adotada uma abordagem denominada panorama informacional em saúde (health information landscape), segundo a qual tal panorama é um complexo espaço de conhecimento socialmente construído, sem limites físicos. Nesses estudos, a autora destaca o elemento resiliência informacional (information resilience), entendido como a "capacidade de adaptar-se, aprender e transformar-se por meio do uso da informação, a fim de reorientar-se, adaptar-se e ajustar-se em resposta à ruptura de panoramas informacionais familiares" (LLOYD, 2016, p. 36, tradução nossa).

Dá-se atenção ao modo como as pessoas conciliam seu panorama anterior - que sofreu ruptura - com a construção de novos panoramas, o que ocorre por meio das experiências dos sujeitos e da socialização. Busca-se entender como as pessoas lidam com a informação, como elas estabelecem relacionamentos, laços sociais e afiliações e, também, como ocorre a transição entre os panoramas. Essas são, segundo Lloyd (2016), formas de capital social, tanto práticas quanto simbólicas, que contribuem para 0 desenvolvimento da resiliência informacional.

Outro conceito proposto por Lloyd (2016) é o de posicionamento (positionality), considerado por ela como relevante em estudos sobre refugiados. O posicionamento está relacionado à postura do pesquisador entendido como outsider, no sentido de não ter vivenciado a experiência de migração - diante de seu objeto empírico. Entende-se que o pesquisador tem uma visão de mundo que pode influenciar sua percepção acerca dos participantes, do contexto e até mesmo do processo de pesquisa. Esse entendimento vai ao encontro da abordagem do contexto relacional, identificado por Courtright (2007) que presume que o olhar do pesquisador influencia a pesquisa. 
Assim, estar vigilante para dar voz a quem vivenciou tal experiência, sem julgamentos por parte do pesquisador, é um aspecto central (LLOYD, 2016). Conforme a autora, o posicionamento possui, portanto, uma dimensão ética, na medida em que os saberes dos participantes devem ser respeitados, ainda que sejam estranhos às experiências do pesquisador. É preciso, ainda, atentar-se a possíveis vulnerabilidades dos participantes, bem como ao fato destes, provavelmente, não dominarem o idioma do pesquisador para que não sejam estabelecidas relações de poder desfavoráveis aos participantes.

\section{CONSIDERAÇÕES FINAIS}

Nesse artigo, esboçamos uma noção acerca do nosso entendimento sobre práticas informacionais. Defendemos uma concepção ampla sobre os elementos presentes na interação dos sujeitos com a informação, estando ela nos mais variados suportes e situações concretas. Isso inclui, portanto, todos os elementos aqui ressignificados, bem como aquilo que sustenta o olhar característico das práticas informacionais: o entendimento de que toda e qualquer ação e/ou opinião do sujeito informacional é fruto de um duplo movimento entre sua subjetividade e os condicionamentos sociais. Assim, ao investigar as práticas informacionais, busca-se compreender o significado que as ações dos usuários têm para eles mesmos e, também, desvelar a dimensão cultural e coletiva por trás de cada uma dessas ações.

Acreditamos que as ideias desenvolvidas ao longo deste artigo - a partir da breve caracterização das abordagens dos estudos de usuários e, especialmente, da explanação acerca da ressignificação pela qual passam diversos conceitos - mostram-se relevantes no atual cenário do campo. A abordagem social e a perspectiva das práticas informacionais têm se fortalecido cada vez mais, não apenas com o aumento na quantidade de trabalhos empíricos produzidos, mas, principalmente, devido aos trabalhos teóricos que se dedicam a debater o tema, discutindo questões sobre os fundamentos teórico-metodológicos que alicerçam esse novo modo de investigar a interação entre usuário e informação. 
Consideramos a adoção da perspectiva de práticas informacionais apropriada para investigações da interação entre sujeitos e informação nos mais variados contextos, como a vida cotidiana, contexto profissional ou acadêmico, dentre outros. Ao abarcar a complexidade dos fenômenos informacionais e ao assumir uma postura compreensiva, estudos que se apropriam dessa perspectiva de práticas informacionais podem revelar categorias passíveis de serem qualificadas; e não quantificadas.

Nessa perspectiva não se intenta apresentar dados ou perfis sociodemográficos a respeito dos sujeitos informacionais e taxas de fontes de informação mais utilizadas. Entendemos que é preciso mais do que trabalhar com dados dessa forma, pois as características ou variáveis investigadas são construções empreendidas na articulação entre os elementos ou dimensões discutidos nesse trabalho e a subjetividade de cada sujeito.

\section{REFERÊNCIAS}

ARAÚJO, C. A. A. Paradigma social nos estudos de usuários da informação: uma abordagem interacionista. Informação e Sociedade, João Pessoa, v. 22, n. 1, p. 145-159, 2012. Disponível em: <http://www.ies.ufpb.br/ojs/index.php/ies/article/view/9896/0>. Acesso: $17 \mathrm{fev}$. 2017.

. O sujeito informacional no cruzamento da Ciência da Informação com as Ciências Sociais. In: Encontro Nacional de Pesquisa em Ciência da Informação (ENANCIB), 14, 2013, Florianópolis. Anais eletrônicos... Florianópolis:

ENANCIB, 2013. Disponível em: $<$ http://enancib.ibict.br/index.php/enancib/xivenancib/paper/viewFile/4181/3304 >. Acesso: 23 fev. 2017.

. Imaginação e sociabilidade: novos conceitos para o estudo de usuários da informação. In: Encontro Nacional de Pesquisa em Ciência da Informação (ENANCIB), 16, 2015, João Pessoa. Anais eletrônicos... João Pessoa:

ENANCIB, 2015. Disponível em: <http://www.ufpb.br/evento/ti/ocs/index.php/enancib2015/enancib2015/paper/vi ew/2981/1045>. Acesso em: 10 fev. 2017.

BARRETO, A. A. A questão da informação. Revista São Paulo em

Perspectiva, São Paulo, v. 8, n. 4, 1994. Disponível em: <http://aldoibct.bighost.com.br/quest/quest2.pdf>. Acesso em: 16 fev. 2017. 
CAPURRO, R. Epistemologia y Ciencia de la Informacion. In: Encontro Nacional de Pesquisa em Ciência da Informação, 5, 2003, Belo Horizonte. Anais... Belo Horizonte: ECI/UFMG, 2003.

CORRÊA, E. C. D. Usuário, não! Interagente: proposta de um novo termo para um novo tempo. Encontros Bibli: revista eletrônica de Biblioteconomia e Ciência da Informação, v. 19, n. 41, p. 23-40, 2014.

COURTRIGHT, C. Context in information behavior research. Annual Review of Information Science and Technology, Malden, v. 41, n. 1, p. 273-306, 2007.

DERVIN, B. Given a context by any other name: methodological tools for taming the unruly beast. In: VAKKARI, P.; SAVOLAINEN, R.; DERVIN, B. (Ed.). Proceedings of an International Conference on Research in Information Needs, Seeking and use in Diferent Contexts, London: Taylor Graham. 1997. p. 13-38.

DIAS, M. M. K.; PIRES, D. Usos e usuários da informação. São Paulo: EdUFSCar, 2004.

DOURISH, P. What we talk about when we talk about context. Personal and Ubiquitous Computing, London, v. 8, p. 19-30, 2004. Disponível em: <http://www.dourish.com/publications/2004/PUC2004-context.pdf>. Acesso em: 22 fev. 2017.

DURAND, G. A imaginação simbólica. Lisboa: Edições 70, 1993.

FERNÁNDEZ MOLINA, J. C.; MOYA-ANEGÓN, F. Perspectivas epistemológicas "humanas" en la documentación. Revista Española de Documentación Científica, v. 25, n. 3, p. 241-253, jul./set. 2002.

FRANÇA, V. R. V. Sociabilidade: implicações do conceito no estudo da comunicação. In: FAUSTO NETO, A.; PORTO, S.; BRAGA, J. L. (Org.). A encenação dos sentidos: mídia, cultura e política. Rio de Janeiro: Diadorim, 1995. p. 55-66.

FREIRE, P. Pedagogia do oprimido. 45. ed. Rio de Janeiro: Paz e Terra, 2007. $213 \mathrm{p}$.

GADAMER, $\mathrm{H}$. The enigma of health: the art of healing in a scientific age. California: Stanford University Press, 1996. 192p.

GANDRA, T. K.; ARAÚJO, C. A. A. Práticas informacionais dos visitantes do Museu Itinerante Ponto UFMG. Em Questão, Porto Alegre, v. 22, n. 3, set./dez. 2016. Disponível em:

<http://seer.ufrgs.br/index.php/EmQuestao/article/view/64326>. Acesso em: 12 fev. 2017. 
GANDRA, T. K. Práticas informacionais dos visitantes do Museu Itinerante Ponto UFMG. 2017. 190 f. Tese (Doutorado em Ciência da Informação) Universidade Federal de Minas Gerais, Escola de Ciência da Informação, Belo Horizonte, 2017.

GEERTZ, C. A interpretação das culturas. Rio de Janeiro: LTC, 2014.

GONZÁLEZ TERUEL, A. Los estudios de necessidades y usos de la información: fundamentos y perspectivas actuales. Ediciones Trea: [S. I.], 2005.

HJØRLAND, B. Library and information science: practice, theory, and philosophical basis. Information Processing and Management, New York, v. 36, p. 501-531, 2000.

JORDAN, B. Authoritative knowledge and its construction. In: DAVIS-FLOYD, R. E.; SARGENT, C. F. (Ed.). Childbirth and authoritative knowledge: crosscultural perspectives. Berkeley, California: University of California Press, 1997. p. 55-79.

LLOYD, A. Building information resilience: how do resettling refugees connect with health information in regional landscapes - implications for health literacy. Australian Academic \& Research Libraries, Londres, v. 45, n. 1, p. 48-66, 2014.

Researching fractured (information) landscapes: Implications for library and information science researchers undertaking research with refugees and forced migration studies. Journal of Documentation, Bingley, v. 73, n. 1, p. 35-47, 2016.

LUNARDELLI, R. S. A. Usuários ou clientes de bibliotecas? Uma reflexão do ponto de vista da lexicologia. SIGNUM: Estudos da Linguagem, Londrina, v. 2, n. 7, p. 91-99, 2004. Disponível em:

<http://www.uel.br/revistas/uel/index.php/signum/article/view/3914/3142>.

Acesso em: 10 fev. 2017.

MARTELETO, R. M. Cultura da modernidade: discursos e práticas informacionais. Revista da Escola Biblioteconomia da UFMG, Belo Horizonte, v. 23, n. 2, p.115-137, jul./dez. 1994.

MCKENZIE, P. J. A model of information practices in accounts of everyday-life information seeking. Journal of Documentation, Bingley, v. 59, n. 1, p. 19-40, 2003.

MICHAELIS. Dicionário Brasileiro da Língua Portuguesa. Disponível em: <http://michaelis.uol.com.br/>. Acesso em: 22 fev. 2017. 
OLIPHANT, T. The information practices of people living with depression: constructing credibility and authority. 2010. $208 \mathrm{f}$. Thesis (Graduate Programme in Library and Information Science). The University of Western Ontario, London, Ontario, Canada, 2010. Disponível em:

<http://ir.lib.uwo.ca/cgi/viewcontent.cgi?article=1049\&context=etd>. Acesso em: 12 mar. 2017.

ØROM, A. Information Science, historical changes and social aspects: a Nordic outlook. Journal of Documentation, Bingley, v. 56, n. 1, p. 12-26, 2000.

PIAGET, J. Biologia e conhecimento. 2. ed. Petrópolis, RJ: Vozes, 1996.

RENDÓN ROJAS, M. A. Hacia un nuevo paradigma en Bibliotecologia. Transinformação, Campinas, v. 8, n. 3, p. 17-31, set./dez. 1996.

. Relación entre los conceptos: información, conocimiento y valor. Semejanzas y diferencias. Ciência da Informação, Brasília, v. 34, n. 2, p. 5261, maio/ago. 2005. Disponível em: <http://revista.ibict.br/ciinf/article/view/1090/1198>. Acesso em: 26 fev. 2017.

ROCHA, J. A. P. A produção do conhecimento como Cognição Distribuída: práticas informacionais no fazer científico. 2018. 210 f. Tese (Doutorado em Ciência da Informação) - Universidade Federal de Minas Gerais, Escola de Ciência da Informação, Belo horizonte, 2018.

ROBREDO, J. Da Ciência da Informação revisitada aos sistemas humanos de informação. Brasília: Thesaurus; SSRR Informações, 2003.

SARACEVIC, T. Ciência da informação: origem, evolução e relações.

Perspectivas em Ciência da Informação, Belo Horizonte, v. 1, n. 1, p. 41-62, jan./jun. 1996.

. Information science. Journal of the American Society for Information Science, Chapel Hall, v. 50, n. 12, p. 1051-1063, 1999.

SAVOLAINEN, R. Spatial factors as contextual qualifiers of information seeking. Information Research, Lund, v. 11, n. 4, 2006. Disponível em: <http://InformationR.net/ir/11-4/paper261.html>. Acesso em: 14 fev. 2017.

. Information behavior and information practice: reviewing the "umbrella concepts” of information-seeking studies. Library Quarterly, Chicago, v. 77, n. 2, p. 109-132, 2007.

TABAK, E. Jumping between context and users: a difficulty in tracing information practices. Journal of the Association for Information Science and Technology, Chapel Hall, n. 65, v. 11, p. 2223-2232, 2014. 
TALJA, S. Constituting "information" and "user" as research objects: a theory of knowledge formations as an alternative to the information man-theory. In: VAKKARI, P.; SAVOLAINEN, R.; DERVIN, B. (Ed.). Information seeking in context. Londres: Taylor Graham, 1996, p. 67-80.

. The Domain Analytic Approach to Scholar's Information Practices. In: FISHER, K. E.; ERDELEZ, S.; MCKECHNIE, L. E. F. (Ed.). Theories of information behavior. Information Today: Medford, New Jersey, 2005. p. 123127.

TALJA, S.; KESO, H.; PIETILÄINEN, T. The production of "context" in information seeking research: a metatheoretical view. Information Processing \& Management, Amesterdã, v. 35, n. 6, p. 751-763, 1999.

TALJA, S.; NYCE, J. M. The problem with problematic situations: differences between practices, tasks and situations as units of analysis. Library \& Information Science Research, Amesterdã, v. 37, n. 1, p. 61-67, 2015.

TALJA, S.; TUOMINEN, K.; SAVOLAINEN, R. "Isms" in information science: constructivism, collectivism and constructionism. Journal of Documentation, Bingley, v. 61, p. 79-101, 2005.

TUOMINEN, K.; SAVOLAINEN, R. A social constructionist approach to the study of information use as a discursive action. In: VAKKARI, P.;

SAVOLAINEN, R.; DERVIN, B. (Ed.). Information seeking in context. Londres: Taylor Graham, 1996. p. 81-96.

VAKKARI, P., SAVOLAINEN, R., DERVIN, Br. (Ed.). Proceedings of an International Conference on Research in Information Needs, Seeking and Use in Different Contexts. London: Taylor Graham. 1997.

VERGUEIRO, W. Qualidade em serviços de informação. São Paulo: Arte e Ciência, 2002.

WHITE, L. A.; DILLINGHAM, B. O conceito de cultura. Rio de Janeiro: Contraponto, 2009.

WILSON, P. Second-hand knowledge: an inquiry into cognitive authority. Westport, CT: Greenwood Press, 1983. 211p.

\title{
INFORMATION PRACTICES: CONSTITUENTS ELEMENTS
}

\begin{abstract}
Introduction: From a brief reference to the traditional and alternative approaches of user studies, these are opposed to the social approach and the studies of information practices. Identifies and discuss the main concepts traditionally addressed in these
\end{abstract}


studies, namely: user, context, information, knowledge and culture. Objective: To present the information practices approach and the reframing of these concepts it's necessary to overcome the perspective based on stimulus-response mechanisms. This perspective is adopted by the first two approaches and need to be changed to fit with this new look at informational phenomena. In addition, other concepts proposed by different authors are presented: sociability, symbolic imagination, authoritative knowledge, cognitive authority, credibility, information resilience and positioning. Methodology: Literature review of the user studies to identify: the way concepts are constructed in each approach and emerging concepts in research on information practices. Results: On a broader understanding than previous approaches, information practices refer to the most diverse modes of interaction between user and information. By adopting the reconstruction of the key concepts of studies, it is assumed that each action of the subject is result of a double movement between his subjectivity and the social references. Therefore, it's necessary to understand the meaning that users' actions has for themselves. Also, it's needed unveil the cultural dimension behind these actions. Conclusions: In information practices, traditional concepts must be reconfigured in order to adjust the more comprehensive view of this perspective. In this sense, the discussion of theoretical-methodological contributions to studies of information practices are relevant to the user studies field.

Descriptors: Users studies. Information practices. Social approach. Context.

\section{PRÁCTICAS INFORMACIONALES: ELEMENTOS CONSTITUYENTES}

\section{RESUMEN}

Introducción: A partir de una breve referencia a los abordajes tradicional y alternativo de los estudios de usuarios, estos son contrapuestos al abordaje social y a los estudios de prácticas informacionales. Se identifica y se discute, posteriormente, los principales conceptos tradicionalmente abordados en estos estudios, a saber: el usuario, el contexto, la información, el conocimiento y la cultura. Objetivo: Presentar la perspectiva de las prácticas informacionales, así como la resignificación de dichos conceptos, que es lo que se necesita para superar la perspectiva basada en mecanismos de estímulo-respuesta, adoptada por los dos primeros abordajes, y para tornarlos acordes con esta nueva forma de mirar los fenómenos informacionales. De manera adicional, se presenta otros conceptos propuestos por diferentes autores: la sociabilidad, la imaginación simbólica, el conocimiento autoritativo, la autoridad cognitiva, la credibilidad, la capacidad de recuperación de información y el posicionamiento. Metodología: Revisión de la literatura de la subárea usuarios de la información buscando identificar: la manera cómo los conceptos son construidos en cada abordaje y los conceptos emergentes en las investigaciones sobre prácticas informacionales. Resultados: En un entendimiento más amplio que los abordajes anteriores, las prácticas informacionales se refieren a diversos modos de interacción entre el usuario y la información. Al adoptar la reconstrucción de los conceptos clave de la subárea, asúmese que cada acción del sujeto es el resultado de un doble movimiento entre su subjetividad y sus referencias sociales. Por lo tanto, es necesario comprender el significado que las acciones de los usuarios poseen para sí mismos y, también, desvelar la dimensión cultural por detrás de estas acciones. Conclusiones: Para el abordaje de prácticas informacionales, los conceptos tradicionales de la subárea deben ser reconfigurados de manera que se ajusten a la visión más

Inf. Inf., Londrina, v. 23, n. 2, p. 566 - 595, maio/ago. 2018. http://www.uel.br/revistas/informacao/ 
comprensiva de esta perspectiva. En este sentido, la discusión de los aportes teórico-metodológicos para estudios de prácticas informacionales son relevantes para la subárea usuarios de la información.

Descriptores: Estudios de usuarios. Prácticas informacionales. Abordaje social. Contexto.

Recebido: 10.03. 2017

Aceito: 27.02 .2018

Inf. Inf., Londrina, v. 23, n. 2, p. 566 - 595, maio/ago. 2018

http://www.uel.br/revistas/informacao/ 